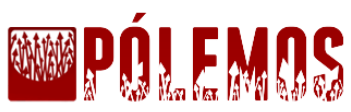

\section{MOUSIKÊ E PAIDEIA NA REPÚBLICA DE PLATÃo}

\author{
Heloíse Cardoso da Silva Aguiar \\ Graduada em Pedagogia e graduanda em Filosofia pela Universidade Federal de Goiás (UFG)
}

\section{RESUMO}

Esse artigo propõe uma reflexão acerca do valor filosófico da música nos livros II e III da República de Platão. Nessa parte da República, a poesia e a música são arranjadas como dois aspectos do conceito de mousikê e Platão prescreve regulamentos e vigilância à criação poética. Após analisar o conteúdo da poesia, nos detemos na análise de como se deve utilizar a palavra, a melodia e o ritmo, que juntos unem poesia e música no conceito platônico de cultura ideal.

Palavras-chave: Platão; Música; Poesia; Palavra; Melodia.

\begin{abstract}
This article proposes a reflection on the philosophical value of music in books II and III of Plato's Republic. In this part of the Republic poetry and music are linked as two aspects of the concept of mousikê and Plato prescribes regulations and supervisions regarding poetic and music creation. After analyzing the content of poetry, we bring into focus the instructions about how we should use word, melody and rhythm, which together join poetry and music in the platonic concept of ideal culture.
\end{abstract}

Key words: Plato; Music; Poetry; Word; Melody.

O termo mousikê, tal como é retratado nos dicionários, significa o que concerne às musas, à poesia ou às artes (MALHADAS, 2008, p. 184). Esse conceito remete também à educação literária e artística. Segundo Rocha Júnior, em Platão "muitas vezes mousikê tem um valor mais abrangente e corresponde às noções 'formação', 'educação' e até de 'filosofia como sabedoria elevada"” (ROCHA JÚNIOR, 2007, p. 43). A observação de Rocha Júnior nos permite enfatizar que o termo mousikê na República nem sempre tem identidade com um conceito estrito de música, derivado da produção de sons e melodias, embora esse sentido faça parte do conceito em algumas seções do texto, como em 398c-412b. Neste trabalho propomos uma descrição da crítica platônica à mousikê nos livros II-III da República, tendo como foco a forma como Platão quer redimensionar esse conceito abrangente de mousikê e, assim, reformar a concepção grega de produção musical. Procuramos mostrar que o conceito 
de mousikê é usado sob duas acepções na República. O primeiro sentido é mais largo e pode ser adequadamente traduzido pela expressão "ciência da harmonia". O segundo sentido é utilizado quando Platão se refere especificamente aos sons musicais, sobretudo a partir de 398c, seção que examina as formas adequadas de canto e melodia na cidade ideal. Desse modo, nosso trabalho procura descrever os argumentos que Platão utiliza, em República II-III, para propor uma reforma na mousikê grega.

A seção I apresenta as linhas gerais das ideias desenvolvidas em República II-II. Na seção II nos concentramos na crítica à poesia de Homero e na seção III, após concluir o comentário sobre a poesia, destacamos o exame platônico das harmonias e ritmos ideais feito em República 398c-412b.

Em A República, o conceito de música está subordinado à concepção platônica de formação filosófica. Tal concepção é tradicionalmente relacionada à paideia, uma noção de cultura intelectual que envolve a formação física e psíquica cujas propriedades centrais estão descritas nos livros V-VII da República. O termo 'paideia', na cultura grega do período clássico, cobre tanto a "educação das crianças" quanto o "conhecimento de artes e ciências liberais" (MALHADAS, 2009, p. 3). Platão sustenta na República que a cultura musical adequada deve ser uma parte da paideia da sociedade ideal. Para sermos mais precisos, devemos observar que Platão sustenta um vínculo entre a música e a formação do caráter. Segundo Crombie:

O alcance da teoria é a música e a dança, embora a tragédia também seja mencionada. A discussão é estabelecida no contexto da educação no sentido de formação de caráter. A bondade que é o objeto da educação é considerada um acordo entre nossas paixões e a razão. Por conseguinte, a educação é a formação de nossas propensões ao prazer e à dor de tal maneira que nós amamos e odiamos as coisas certas. (CROMBIE, 1962, p. 190). ${ }^{1}$

Em Platão, portanto, a educação musical depende de uma concepção filosófica de bem que molda o caráter do indivíduo de um modo que lhe permite, de um lado, apreciar os objetos corretos e, de outro, se afastar dos objetos moralmente inadequados (Rep., 376 e; $377 a)$.

\footnotetext{
${ }^{1}$ “The scope of the theory is music and dancing, though tragedy is also mentioned. The discussion is set in the context of education in the sense of character-training. The goodness which is the object of education is said to consist in agreement between our passions and reason, and education is therefore the shaping of our propensities to pleasure and pain in such a way that we love and hate the right things".
} 
Essa educação se dá nos níveis físico e psíquico do indivíduo. O cuidado do corpo, por meio da ginástica, trata do nível físico, e o aspecto psíquico tem na música uma parte fundamental de sua realização. Contudo, para Platão a música não deve educar exclusivamente a alma, assim como a ginástica não deve ser um exercício que vise apenas à saúde do corpo. Música e ginástica devem ser exercitados de forma complementar e harmônica. Segundo Platão, a educação centrada exclusivamente na ginástica leva à aspereza do homem e a educação musical com vistas apenas ao desenvolvimento das melodias conduz à excessiva delicadeza. Platão afirma que “(...) aquele que reúne de modo mais perfeito a ginástica e a música e as aplica na melhor medida à própria alma, aquele diremos nós mui justamente, é perfeito músico e perfeito harmonista” (Rep. 412a). Quanto à ginástica, sua finalidade não é alcançar a força física de um atleta profissional, mas desenvolver a coragem e a boa disposição física do guardião da cidade.

A República retrata uma relação íntima entre a música e a filosofia. $\mathrm{O}$ advento dessa relação não coincidiu, como se poderia imaginar, com o declínio do mito na época em que a filosofia ganhou força na produção dos pensadores pré-socráticos, pois essa relação já estava presente na cultura dos poemas homéricos. Como mostra Asmis, "os poemas eram entoados ou cantados, geralmente com acompanhamento instrumental, em encontros que iam de reuniões privadas a celebrações de que participavam toda uma comunidade ou região." (ASMIS, 2013, p. 400). A investigação que Platão promove na República procura mostrar que na cidade ideal - cujos traços são moldados, no livro II, tendo em vista a necessidade de definição dos conceitos de justiça e injustiça - a música e a ginástica exercem um papel preponderante (Rep. 377d). Na próxima seção iremos retomar o contexto no qual essa tese é argumentada, visando esclarecer o escopo da concepção platônica de educação musical.

O tema que propomos desenvolver aqui é relevante também pelo fato de existir certa polêmica no modo como Platão critica a noção de música (mousikê) na República. Quando critica a mousikê grega Platão se serve de razões filosóficas para delimitar um conceito bem preciso de música e nesse movimento ele rejeita alguns gêneros musicais na cidade ideal. Quando retirada de seu contexto essa imposição de limites aos gêneros musicais provoca estranhamento ao leitor, mas é preciso notar que as críticas platônicas à cultura musical, na República, se constituem num quadro em que a música é um aspecto da cultura poética, da qual os mitos e textos constituem as demais partes (Rep. 398b-c). Enquanto produção artística no contexto da educação dos guardiões, a poesia - e a música que a acompanha - deve estar subordinada à filosofia e aos conceitos reguladores da cidade ideal. O poeta se encarrega da 
formação moral e a filosofia de assuntos mais elevados, como a estruturação dos princípios filosóficos da sociedade. Mas a crítica de Platão não visa substituir a poesia pela filosofia. Como afirma um importante intérprete da paideia platônica“"...] nem se quer passa pela cabeça de Platão que a poesia, considerada como potência educadora, possa ser substituída pelos conhecimentos abstratos da filosofia" (JAEGER, 2011, p.782). Seu objetivo é reformar a cultura poética para que ela se adapte aos valores da sociedade ideal, cujos traços estão sendo propostos no texto de toda a República. Para Platão, a representação dada pela poesia como um tipo de música toca diretamente a alma das crianças, razão pela qual tais representações não podem ser entregues à liberdade do artista (Rep. 377a-c). É exatamente esse o ponto mais polêmico, pois numa concepção moderna, ou mesmo histórica, a arte sempre reivindica liberdade de criação e de representação.

Assim, nosso objetivo é compreender como Platão concebe o conceito de mousikê e de que modo ele imagina poder reformar a concepção de mousikê tal como é praticada em seu tempo. O primeiro ponto relevante a ser observado já foi mencionado acima. Para os gregos da época de Platão, a música não é um gênero artístico neutro. O termo mousikê abrange música e poesia porque ambas são experimentadas em conjunto. Portanto, a música não é um gênero limitado aos sons de instrumentos e atividades vocais. Notemos que a República diz que os discursos (logoi) são considerados parte da mousikê (Rep. 376e). De um modo geral, podemos dizer que a mousikê é a atividade artística desempenhada sob o efeito das musas (MALHADAS, 2008, p. 184). A autoria das obras poéticas era atribuída às musas e os poetas eram somente os portadores da palavra divina. Neste sentido, o conteúdo poético e musical atuava como produto divino e o poeta ostentava o posto de artista que tem contato com os deuses.

Não é por acaso, desse modo, que tão logo conclui a elaboração do desenho inicial da cidade ideal, no livro II, a República começa a tratar do conceito de mousikê e do tipo de formação que o estado fornece às crianças.

O modelo de educação platônico tem como fim a formação de governante filósofo com uma educação de nível superior, porém, antes disso, ele pensa que no corpo da República é necessário revisar os modelos de cultura vigentes. A instrução primária por meio da mousikê e da ginástica proporciona à alma fundamentação para continuar nos estudos superiores. Nesta primeira etapa, todas as crianças com vocação para o posto de guardiãs devem ser educadas juntas e devem receber o mesmo tipo de instrução, cuja concepção fica a cargo do 
Estado. Segundo Platão, os jovens devem ser educados por uma música com padrões estabelecidos, que leve à virtude, coragem e razão.

Os elementos musicais são associados ao comportamento moral da audiência e diferentes combinações levam a certos tipos de comportamento ${ }^{2}$. A palavra, o ritmo e a melodia devem respeitar normas e zelar para a manutenção da legislação.

É importante enfatizar, também, que Platão não está redefinindo todos os contornos da educação musical ateniense, pois alguns paradigmas já estavam postos. Atenas, nesse sentido, já tinha um ideal de educação bem estabelecido. É sabido que Atenas se diferenciava de Esparta no aspecto do tipo de educação, embora nem sempre tenha sido assim. Segundo Ferreira,

Esparta e Atenas tinham, na época clássica, tipos de educação sensivelmente diferenciados. Mas nos primeiros tempos isso não acontecia. Nos primórdios, a educação tinha por finalidade a preparação do cidadão para a defesa do seu país. Era por isso, de início, um ensino apenas militar, que incluía evidentemente os exercícios físicos. Pretendia adestrar no manejo das armas os futuros defensores da polis (FERREIRA, 2010, p. 23).

Esparta e Atenas possuíam uma estrutura de poder e um caráter individualista, pois cada cidade se comportava como independente e autônoma, o que resultava em constantes conflitos com as cidades vizinhas. Todos os cidadãos eram preparados para se apresentarem nas batalhas e tinham uma educação militar que os formava para tal meta. O ideal de homem na época valorizava a coragem e a habilidade nos combates. É nesse sentido que Ferreira afirma que Esparta e Atenas tinham tipos de educação sensivelmente diferenciados, pois cada uma passou por crises que as levaram a diferentes formas de solução para o problema da educação. Esparta passou a ter um ideal militar, com obsessão pela educação do corpo, tornando-se uma potência militar, o que certamente contribuiu para que ela diminuísse sua riqueza cultural em detrimento da formação intelectual. Atenas, de seu lado, procurava o equilíbrio entre a formação do espírito e o treinamento do corpo. O cuidado com o corpo tinha o objetivo de torná-lo sadio, forte e belo. A educação ateniense estava ligada ao desenvolvimento da personalidade com ênfase na formação espiritual. Em Atenas o conceito de conhecimento, que antes estava baseado nos textos dos antigos poetas, passou a desenvolver técnicas de argumentação e persuasão, porém, essa educação era restrita a quem possuía condição de pagar um professor particular. Assim, havia certo elitismo na educação ateniense. Como destaca Ferreira:

\footnotetext{
${ }^{2}$ Os padrões estabelecidos para música e seus elementos serão tratados adiante.
} 
Mas nessa época, a par da guerra e da preparação para ela, deparamos com uma cultura que lentamente evoluía e se afirmava. Os nobres, além de se dedicarem a atividades relacionadas com o governo e defesa da pólis, levavam uma vida de requinte, apreciavam a arte, a poesia e a música e entregavam-se aos exercícios físicos (FERREIRA, 2010, p.16).

$\mathrm{Na}$ tradição grega a poesia era importante fonte de conhecimento e os poetas eram vistos como autoridades intelectuais. A poesia possuía um vínculo estreito com todas as poleis, inclusive em Esparta. Os nobres se dedicavam à atividade física, mas também apreciavam a arte, a música e a poesia. Havia três tipos de mestres: o da ginástica, chamado "paidotriba" (FERREIRA, 2010, p. 25), o mestre das letras, chamado "gramático", e o mestre da música e poesia, chamado "citarista". O ensino da música começa a ter importância maior quando Atenas passa a dar ênfase aos discursos por razões políticas. Como sustenta Ferreira:

(...) no decurso dos séculos VIII a VI a. C. a necessidade de intervir no Conselho e na Assembleia, um órgão colegial o primeiro e constituído por todos os cidadãos a segunda, obriga o dirigente a ter de usar da palavra e a saber convencer os seus concidadãos. Assim aparece o ensino da música, através do citarista, o mestre que, talvez a partir do século VI a.C., ensinava as crianças a tocar cítara, e o das primeiras letras, a cargo do gramatista que ensinava a ler e a escrever e cuja existência parece datar dos inícios do século $\mathrm{V}$ a.C. (FERREIRA, 2010, p. 26).

O ensino da música, citado acima como complementar ao ensino das letras, tratava de discursos (Rep. 376e). Entre os discursos, naturalmente, Platão identifica elementos falsos e verdadeiros e sugere que as crianças devem ser educadas com ambos, pois os discursos falsos, sob a forma de mitos, também podem ter um efeito pedagógico benéfico se o conteúdo de tais mitos compreender uma verdade (idem). Platão entende que a criança não tem maturidade para diferenciar verdade e falsidade, pois essa diferenciação é sinal de uma cultura amadurecida na alma, algo que as crianças ainda não possuem. Elas aprendem de acordo com o que ensinamos, e, porque ainda não sabem discriminar o falso do verdadeiro, é preciso trabalhar com os conceitos verdadeiros, cabendo aos falsos apenas o efeito pedagógico do mito. Assim, as primeiras histórias que as crianças ouvem devem direcioná-las para o conhecimento da verdade.

Portanto, seria preciso antes de tudo, parece, vigiar os fazedores de fábulas, escolher suas boas composições e rejeitar as más. Obrigaremos, em seguida, as mães e as nutrizes a narrar às crianças aquelas que tivermos escolhido e a modelar a alma com suas fábulas muito mais do que os corpos com suas mãos; mas as que elas narram presentemente devem, em sua maioria, ser rejeitados (Rep. 377c). 
Nesse trecho pode-se observar que Platão revela uma preocupação com o conteúdo do que a criança ouve e lê. A poesia, por meio de seus textos, possui um caráter educativo na vida das crianças e por isso deve ser vigiada de maneira que haja uma seleção do que é adequado. Platão não somente quer censurar a influência negativa de certos traços da poesia e da música na mente das crianças vocacionadas para o governo. Seu objetivo, no contexto do que ele diz nos livros II-III, parece ser mais alto. Ele quer redimensionar toda a concepção de poesia e música sob a perspectiva da ética. Por essa razão, ele se dedica em boa parte do texto a tecer relações entre o caráter do indivíduo e certos conteúdos que este aprecia e apreende.

Assim, entendemos que há material nos texto de Platão para compor um quadro mais ou menos nítido sobre o modo como o autor dos diálogos concebe a educação musical. Nas linhas que seguem, por meio da ênfase a algumas passagens de República II-III, vamos expor as características da concepção platônica da música como parte da formação do jovem ateniense.

Nos livros II e III Platão se concentra, em primeiro lugar, no conceito de poesia como meio para educar as crianças. O conceito de poesia trata dos mitos ou histórias sobre deuses contadas na infância. Platão entende que a poesia deixa uma marca muito forte nas crianças porque elas estão numa fase de formação de identidade e ele tem em vista a formação das crianças para desempenharem a função de um guardião. Os guardiões serão os responsáveis pelo bem-estar da cidade. Eles são selecionados por meio de observação de seus traços intelectuais e físicos desde a infância; devem ter características como boa percepção sensorial, agilidade e coragem. Para compor tais traços, Platão sugere aos guardiões, assim como aos outros cidadãos, que tenham contato apenas com conteúdos benéficos.

A cultura grega considerava que os poetas eram pessoas inspiradas pelos deuses. $\mathrm{O}$ discurso feito pelo poeta era tido como uma verdade inquestionável, pois a palavra poética vem das musas e tem um efeito de afinidade e encantamento no público. Essa cultura, portanto, via os poetas como sábios; eles tinham conhecimentos sobre o passado, o presente e o futuro e tais informações eram expressas por meio das performances orais de seus poemas. Assim, eram comuns as representações em que o destino do homem, não importa se bom ou ruim, era definido pela ação dos deuses. Em A República, Platão faz uma crítica a esse tipo de representação e afirma que deuses e heróis, enquanto exemplos do bem, não podem ser 
representados sob a forma de personagens negativos, causadores de desordem ou violência. Platão diz que é preciso:

[...] vigiar ainda os que se dedicam a contar essa espécie de fábulas e pedir-lhes que não censurem, de maneira simplista, as coisas do Hades, mas antes que as elogiem; pois seus relatos não só não são verdadeiros como também inúteis a futuros guerreiros (Rep. 386c).

Platão sugere uma censura que corrija a natureza e a imagem dos deuses e heróis. Os gregos acreditavam na existência do Hades como o mundo dos mortos. Para compor uma boa compreensão do Hades, como quer Platão, devemos fazer elogios à condição dos que lá estão para que, assim, os guardiões não tenham medo da morte, sentimento que poderia levá-los a temer a posse da coragem como conceito e como motivo na ação.

Por outro lado, Platão afirma que falar de um conteúdo essencialmente bom sobre o Hades comporta outro aspecto fictício: é uma mentira que transmite um valor ligado ao bem. Nesse sentido, trata-se de uma mentira útil quando utilizada em relação aos inimigos, amigos em delírio ou fábulas nas quais o conteúdo é referente a um passado cuja verdade não sabemos. Quando a mentira beneficia a cidade, ela é classificada positivamente, mas se algum cidadão, excetuando-se os chefes da cidade, mentir, Platão entende que nesse caso ele pode prejudicar toda a cidade. Ele afirma que "[...] se a alguém compete mentir, é aos chefes da cidade, para enganar, no interesse da cidade, os inimigos ou os cidadãos; a qualquer outra pessoa a mentira é proibida" (Rep. 398c).

Para Platão, a justiça no Estado baseia-se em cada um cumprir com excelência sua função determinada (Rep. 429a). Devido às características próprias, o grupo dos governantes é menos numeroso. Sua alma contempla a verdade, a qual faz dele um indivíduo apto a governar a cidade da melhor forma. Desse modo, os governantes devem ser os filósofos, pois somente estes sabem diferenciar opinião e ciência. Essa tese se justifica, em Platão, no fato que o conceito de ciência tem sempre relação com o bem, mas para compreendê-la plenamente é preciso estar na posição de quem se dedica a seu estudo. Nesse sentido, a verdade não é para todos.

Dentro desse quadro profundamente reformador, a música precisa ser regulamentada para ser aceita como parte integrante da sociedade ideal. Platão afirma que deve haver uma reforma não apenas no conteúdo da música, mas em sua forma, no estilo da linguagem 
musical. Devem ser mantidos apenas os estilos que contribuem para a formação de uma conduta moral no homem. A ideia de estabelecer uma reforma musical está ligada à reforma das normas educativas da cidade ideal. São três tipos de narração poética que caem sob o exame dessa reforma. De acordo com A República:

[...] há uma primeira espécie de poesia e de ficção inteiramente imitativa que abrange [...] a tragédia e a comédia; uma segunda, em que os fatos são relacionados pelo próprio poeta, e hás de encontrá-la sobretudo nos ditirambos, e enfim uma terceira, formada pela combinação das duas precedentes, em uso na epopeia e em muitos outros gêneros (Rep., 394c).

A imitação dramática é a narração na qual os poetas imitam a pessoa narrada, uma forma comum às tragédias e comédias. As narrações simples são feitas pelo próprio poeta e encontradas geralmente nos ditirambos, que são cantos alegres ou sombrios constituídos por uma parte narrativa. A última é a combinação dos tipos anteriores de discurso, utilizada em epopeias e outros gêneros.

Sobre a relação entre tais narrativas e a educação dos guardiões Platão afirma que:

(...) se imitarem, que sejam as qualidades que lhes convêm adquirir desde a infância: coragem, temperança, pureza, liberalidade e outras virtudes do mesmo gênero; mas não devem praticar nem saber habilmente imitar a baixeza, nem qualquer dos outros vícios, por medo de que, da imitação venham encontrar prazer na realidade (Rep. 395c).

Assim, nota-se que Platão considera que a imitação possui grande influência no caráter do indivíduo. É por esse motivo que os guardiões devem utilizar a imitação especificamente nos casos nos quais as pessoas ou os valores imitados são nobres e virtuosos. Pode-se observar que Platão admite a imitação na educação dos guardiões na condição de que os modelos imitados possuam semelhança com os conceitos que estruturam essa educação. De outro lado, Platão também irá ressaltar que a linguagem de um homem de bem, como deve ser o guardião, não pode ter muitas variações. Ela deve cultivar a uniformidade. Platão contrasta essa característica com a produção dos poetas e artistas em geral, os quais possuem uma linguagem com acompanhamento musical, ritmo e muitas variações. Como afirma Jaeger:

Aos artistas deste gênero moderno e cheio de encantos são prestadas no Estado platônico todas as honras e toda admiração, ungem-lhes a cabeça e adornam com fitas de lã; mas, uma vez honrados, acompanham-nos a outra cidade, visto que não há lugar para eles no Estado puramente educador. (JAEGER, 2011, p.785) 
A categoria de artistas mencionada é vista como composta de sujeitos que, na aparência, são capazes de imitar tudo para exibir seus poemas. Embora pareça estranho que Platão se coloque contra tal habilidade, é preciso situar sua análise no contexto do princípio de especialização defendido no livro IV (Rep. 374a; 433a). Segundo esse princípio, cada pessoa deve exercer apenas uma função dentro da cidade. Se a arte e a música devem refletir os conceitos ideais, então ela não pode representar indivíduos que desenvolvem em sua alma os efeitos opostos do princípio de especialização. Desse modo, tais artistas serão bem recebidos na cidade ideal como visitantes, mas não como cidadãos, pois a arte que produzem não está em conformidade com os padrões aceitáveis. Portanto, os poetas e narradores da República devem ser mais formais e menos interessados em agradar, devem imitar o tom do homem de bem e seguir as regras já estabelecidas.

Quando trata especificamente das melodias e ritmos, a partir de 398c, Platão enfatiza que algumas harmonias devem ser mantidas e outras banidas. Como a música é exibida junto com o pronunciamento dos textos da poesia, Platão enfatiza que harmonia e ritmo devem acompanhar a palavra (logos) (Rep. 398d). Quanto às harmonias, a educação ideal deve considerar impróprias as que propiciam ocasião para choros e lamentações (idem). Exemplos de tais harmonias são a mixolídia e a sintonolídia (Rep. 398e). De outro lado, harmonias que favorecem na audiência a manifestação de comportamentos como languidez e ociosidade também devem ser evitadas e as harmonias jônia e lídia são desse tipo (idem). Seriam conservadas, contudo, as harmonias dória e frígia. A primeira porque imita a virtude da coragem, sobretudo nos campos de batalha, e a segunda porque sugere a ação voluntária da moderação e persuasão. Assim, harmonias associadas a comportamentos inadequados, como preguiça, embriaguez e as que deixam os homens mais lamentosos e contidos, devem ser eliminadas. Essas harmonias são identificadas na República como "jônia", "lídia mista", "lídia aguda" e similares. As harmonias dóricas e frigia são associadas, respectivamente, à imagem de um guerreiro bravo e corajoso e à ação de um homem empenhado em uma ação pacífica e voluntária (ROCHA JÚNIOR, 2007 p.38-40).

As possíveis combinações musicais tornam as pessoas mais ou menos dispostas a certas ações. A cada elemento musical é associado um comportamento moral, nas melodias e ritmos há imitação de caráter, e por serem diferentes não levam ao mesmo comportamento. Deste modo os elementos musicais devem ser escolhidos cuidadosamente de forma que conservem a identidade psíquica do indivíduo. 
Em seguida, a República examina quais instrumentos devem ser mantidos. Os triângulos, espécie de harpas com sons agudos, são banidos, bem como todos os instrumentos de muitas cordas ou que produzem muitos sons, como flautas. São mantidas a lira e a cítara (Rep. 399d-e). Não há, portanto, necessidade de instrumentos com muitas cordas, admitindose como vitais apenas a lira e a cítara por produzirem melodias simples. Instrumentos com excessivas variações levam a comportamentos potencialmente contrastantes.

Junto da harmonia está o ritmo, que é a ordem no movimento e também não deve apresentar muitas variações. Ele deve expressar uma vida regrada e corajosa. Para questões de aprofundamento técnico Platão afirma que há a opção de dirigir-se ao músico Dámon, uma autoridade no tema da relação entre música e ética (ROCHA JÚNIOR, 2007, p. 39). Dámon pode instruir sobre quais ritmos levam à baixeza, insolência, loucura e outros vícios, os quais, naturalmente, devem ser evitados. O interesse de Platão está na influência do seu aspecto moral e não na especificidade da teoria musical.

\section{IV}

Ao concluir sua análise da educação musical no livro III, Platão refere-se à influência da pintura e outras artes que também devem ser compostas segundo padrões de graciosidade (euschêmosune) (Rep. 401a). Não são apenas os poetas que devem criar imagens do bem, mas todos os outros artistas devem fazer da mesma forma. Assim como a pintura, o tecer, o bordar, toda arte deve expressar beleza e decência, de maneira que ajude a criar qualidades morais na alma do jovem. Quanto à música, claramente se trata do conceito que mais bem representa essa ideia de harmonia e moderação na alma. Como destaca Burnyeat:

A música é decisiva devido à influência em seu senso de beleza, - seu gosto, assim o século dezoito o chamou - que por sua vez orienta sua resposta a outros aspectos do ambiente. Desta forma, a música é incluída no mesmo âmbito da cultural material e moral. E não é só música no sentido limitado de ritmo e harmonização. A palavra de Platão mousikê envolve música e poesia juntas, porque no mundo antigo você normalmente as ouve junto, como canção". (BURNYEAT, 1997, p. 222) ${ }^{3}$

\footnotetext{
3 "Music is decisive because of its influence on your sense of beauty - your taste, the eighteenth century called it - which in turn guides your response to other things in the environment. In this way, music is included in the same range as material and moral culture. And not only music in the narrow sense of rhythm and attunement. Plato's word mousike covers music and poetry together, because in the ancient world you usually hear them together, as song".
} 
Como se vê, ainda que esteja irremediavelmente atrelada ao conceito de poesia, a mousikê é decisiva porque influencia a percepção do conceito de beleza e esse conceito é crucial na República. A mousikê penetra fundo na alma e afeta mais fortemente que as outras artes, de modo que a educação musical deve antecipar o conhecimento filosófico. Isso justifica, no quadro da República, a proposta de vigiar a poesia e o conteúdo dos versos para que reflitam a imagem do que é bom e belo.

A proposta platônica, desse modo, envolve uma reforma na concepção de mousikê e implica uma nova disposição na audição e leitura das obras poéticas. Até então, tratava-se de ouvir textos poéticos como canção, mas sem se preocupar com o conteúdo desses textos e seus efeitos na alma. Platão impõe normas e restrições que vão permitir à nova mousikê preparar o espírito dos futuros governantes da cidade ideal. Sua interpretação da influência de algumas harmonias no comportamento deve ser compreendia no quadro da tese de que dentro da cidade cada atividade, seja filosófica, técnica ou artística, deve ter uma função específica em relação aos valores e princípios que organizam o todo. Embora, para um leitor moderno, esse aspecto moral da produção musical pareça uma tese despropositada, já que limita as formas e expressões artísticas aceitas e submete a profissão a um regramento externo à técnica, Platão não parece, nos livros II a III da República, preocupado com a música enquanto tal. Claramente seu foco é o tipo de produção que emerge da produção musical como exibição de harmonias e ritmos durante a performance poética. Nesse sentido, seu principal ponto é a tese de que a educação das formas musicais aceitáveis é uma necessidade do propósito de manter a harmonia na sociedade. Se o preço a pagar é a expulsão de certos modos musicais, é preciso também considerar que o conceito de beleza impõe certas necessidades e enquadramentos à apreciação do que é belo e de seu contrário.

\section{REFERÊNCIAS BIBLIOGRÁFICAS}

ABBAGNANO, Nicola. Dicionário de Filosofia. São Paulo: Martins Fontes, 2000.

ASMIS, Elizabet H. Platão sobre a criatividade poética. In: KRAUT, 2013, p. 399-430.

BENSON, Hugh. H. Platão. Porto Alegre: Artmed, 2011.

BURNYEAT, Myles Fredric. "Culture and Society in Plato's Republic”. Tanner Lectures on Humans Value 20, 1997, p. 217-324. 
CROMBIE, Ian M. An Examination of Plato's Doctrines: I Plato on Man and Society. London: Routledge, 1962.

FERREIRA, José Ribeiro. Educação em Esparta e Atenas: dois métodos e dois paradigmas. In: LEÃO, FERREIRA \& FIALHO, 2010, p.11-45.

JAEGER, Werner. Paidéia: a formação do homem grego. São Paulo: Martins Fontes, 2011.

JANAWAY, Christopher. Platão e as Artes. In: BENSON, 2011.

KRAUT, Richard. Platão. São Paulo: Ideias \& letras, 2013.

LEÃO, Delfim Ferreira; FERREIRA, José Ribeiro; FIALHO, Maria do Céu Fialho. Cidadania e Paideia na Grécia Antiga. Coimbra: Editora CECH, 2010.

MALHADAS, Daisi. (Coord.). Dicionário Grego-Português, v.1-5. Cotia, Ateliê Ed., 20062010.

PLATÃO. A República. Tradução de Ana Lia A. A. Prado. São Paulo: Martins Fontes, 2006. A República. Tradução de J. Guinsburg. São Paulo: Perspectiva, 2010.

ROCHA JÚNIOR, Roosevelt Araújo da. "Música e Filosofia em Platão e Aristóteles". Revista Discurso, Universidade de São Paulo, n. 37, 2007. 